\title{
Do Japanese Undergraduates Think They Will be in an International Environment?
}

\author{
Liang Morita ${ }^{1}$ \\ ${ }^{1}$ Graduate School of Languages and Cultures, Nagoya University, Nagoya, Japan \\ Correspondence: Liang Morita, Graduate School of Languages and Cultures, Nagoya University, Nagoya, Japan. Tel: \\ 81-52-789-3515. E-mail: liang@lang.nagoya-u.ac.jp
}

Received: November 11, 2013

Accepted: November 24, 2013

Online Published: December 1, 2013

doi:10.5430/ijhe.v3n1p58

URL: http://dx.doi.org/10.5430/ijhe.v3n1p58

\begin{abstract}
Based on a data of 217 responses to questionnaires and conducted at a top Japanese national university, this paper examines the objective of preparing students to function in an international and intercultural context in the internationalisation of universities. Many educators have proceeded to internationalise the curriculum based on this objective but few have stopped to ask students if they really think they will be in an international environment. This question is particularly pertinent in Japan given its sakoku ('closed country') history and the recent description by the government of young people as being inward-looking. The author found that although some young people are influenced by sakoku thinking, many are outward-looking and positive about globalisation. There is however a tendency to perceive globalisation as an abstract concept and not engage with it. Students in engineering and science are more likely to perceive themselves working in an international environment compared to literature and law students.
\end{abstract}

Keywords: Japan, Globalisation, Internationalisation, Intercultural context

\section{Introduction}

The internationalisation of universities is by now a common process that can be observed all over the world. The process of internationalisation usually involves introducing an international dimension to the curriculum, which has been taking place in as early as the mid-nineties, when Knight and de Wit (1995) noted that higher education institutions are giving more importance and priority to integrating an international dimension into their teaching/learning, research and services. The authors emphasise the importance of preparing students for an international milieu:

'Internationalisation efforts are intended to enable the university/college community to have the ability to understand, appreciate and articulate the reality of interdependence among nations (environmental, economic, cultural and social) and to prepare faculty, staff and students to function in an international and intercultural context.'

(Knight and de Wit, 1995:13)

Students need to be prepared to function in intercultural contexts not only in their future but also in their present intercultural university life. Implicit in the quotation above is the assumption that students will find themselves in an international environment. Many educators and researchers have since cited Knight and de Wit in their work on internationalising the curriculum (e.g. Hamza, 2010; Montgomery, 2009; Whitsed and Volet, 2011), which is by now a substantial part of internationalising the institution. An internationalised curriculum is defined as:

'Curricula with an international orientation in content, aimed at preparing students for performing (professionally/socially) in an international and multicultural context, and designed for domestic students and/or foreign students.'

(Knight and de Wit, 1995:14)

However, few have stopped to ask if students themselves think they will be in an international environment. An internationalised curriculum aimed at preparing students for intercultural contexts would be ineffective if the students think it unlikely to be in such contexts. Knight and de Wit also observed that 'even students who never leave their own country are affected by the impact of our globalised society and economy', which is again open to debate as to 
whether students think their home country is affected by globalisation.

This paper challenges the assumption that university students think they will be in an international environment and whether Japan is affected by globalisation. These are particularly pertinent questions in the Japanese context given the sakoku ('closed country') history of Japan and the recent fall in the number of Japanese students going abroad to study, which I elaborate on below.

In the literature on Japanese studies, some authors have written about the country's unwillingness to open up to the world. One of them, Itoh (2000), explains the attitude by citing sakoku, the 250 years of self-imposed isolation from the rest of the world which took place from 1639 to 1868. She argues that the pervasive Japanese attitude of exclusiveness and parochialism stems from two powerful roots: the country's geographic isolation as an island nation and the history of sakoku. Itoh believes that the sakoku mentality still influences the way the Japanese think, behave and relate to the world. Although the country's manufacturers are keen to flood the world with their products, the ubiquity of Japanese goods is not matched by the presence of Japanese working for the world. Traditional characteristics of insularity and parochialism are still preserved and the sakoku mentality still lingers and underlies modern Japanese ways of thinking and behaving.

Along similar lines, Dougill (1995) argues that the Japanese have no real interest in integrating with the international community due to a deeply ingrained form of cultural conditioning. This is supported by Clammer (2001) and Itoh (2000), who also point out a lack of interaction with the international community. In addition, Clammer observes that Japanese society does not reward individuals who put the rhetoric of internationalisation into practice. Examples are Japanese graduates of foreign universities who are discriminated against when seeking employment and company employees who resist being posted overseas because they will be left out of the inner political circles in the organisation.

Burgess (2013) also supports the above view about Japanese companies. Although some high-profile Japanese companies such as Rakuten are exceptions, Japanese hierarchical corporate culture can be uncomfortable with confident and outspoken returnee students. A number of Japanese with study-abroad experience found Japanese companies unenthusiastic and reluctant to hire them. In a survey of 1,000 companies on their recruitment plans for the fiscal year 2012, less than a quarter said they planned to hire applicants who had studied abroad.

Attitudes towards globalisation in Japan are not unanimously positive either. Yamagami and Tollefson (2011) found an ambivalence towards globalisation within the government. Globalisation is perceived as an opportunity as well as a threat. In many instances in which globalisation is represented as an opportunity, the government emphasises that both individuals and the nation must develop new skills (especially in technology and English) in order to meet the challenges. On the other hand, Diet (parliament) discourse articulates the threats that globalisation presents: violent crime, reduced personal and national security, and a sense of loss and uncertainty about the future.

A recent government report (The Council on Promotion of Human Resource for Globalisation Development, 2011) acknowledges the fall in the numbers of Japanese going abroad to study since 2004 and describes the nation's young people as having an 'inward tendency'. It also reports that young people increasingly do not wish to work overseas. The document is presented as part of government efforts to counteract these tendencies, called the Project for Promotion of Global Human Resource Development. The project is still in its early stages and the effects remain to be seen.

The term kokusaika, which is the most commonly used term to refer to the process of internationalisation, captures the ambivalence towards globalisation. The use of kokusaika first became popular in the context of the early 1980s, when Japan had enjoyed almost 20 years of astounding economic growth, became the world's largest creditor nation and more Japanese began to travel overseas. (Goodman, 2007) Outwardly, kokusaika may refer to the process of internationalisation similar to those seen in other nations, but the meaning of a Japanese-only nationalism that reinforces a closed national identity has been dominant and has flourished with financial support from government and business leaders. (Burgess et al., 2010) English language education in Japan is an illustration of kokusaika, of how something outsiders may perceive as internationalisation serves the purpose of strengthening national identity and protecting national interests. Although the government has taken many steps over the years to develop English education, such as introducing English in elementary school in recent years, many have interpreted them as measures to train the Japanese to use English to promote, enhance and defend Japanese interests and independence. (Burgess et al., 2010) Another example is the government plan to expand the number of overseas Japanese language facilities 10 -fold which was announced soon after the target of having 300,000 foreign students in Japan by the year 2020 was set. These international students have to learn about Japanese language and culture, based on the belief that as part of kokusaika, there should be recognition of Japanese culture and society. Kokusaika is thus a challenge to preserve 
Japanese identity, national unity and economic power, a defensive reaction to pressure from other nations' criticisms of Japan's economic self-centredness and cultural insularity.

As we have just seen, kokusaika is not usually used to describe the phenomenon of the world becoming increasingly interconnected. Gurobaruka, which is based on the English 'to globalise' or 'globalisation' and has adapted to Japanese phonology, corresponds closely to the English meaning of a growing interconnectedness in the world. The main difference between kokusaika and gurobaruka is that Japan has control over and is an active participant in the former but the latter is an external process over which Japan has little or no control.

In this context of the development of national identity and protection of national interest in the name of internationalisation, it is not surprising that the intercultural aspects of the internationalisation of universities have been neglected. There is a lack of emphasis on fostering intercultural development at both individual and institutional level. (Whitsed and Volet, 2011) In universities, kokusaika has historically been understood to refer to pragmatic processes that largely ignore the intercultural dimensions of internationalisation. According to Goodman (2007), the kokusaika discourse creates impressions or appearances of a forward looking, progressive suite of policies and initiatives towards intercultural understanding but lacks substance.

Although there have been attempts to emphasise the intercultural aspects of internationalisation such as study abroad programmes for Japanese students collaborative programmes between Japanese and foreign universities, cases of oversight are more frequent. (Whitsed and Volet, 2011) One of such oversight is the use of English language education as a tool to develop national identity and protect national interest rather than to foster students' intercultural communication skills. This contrasts sharply with language learning as a means to develop intercultural competence in the Anglo-European literature.

The present study is based on a data of 217 responses to questionnaires. The author found that although sakoku mentality still has some influence, there are also many who are outward-looking and positive about globalisation. The most important factor which influences students' answers as to whether they think they will be in an international environment is their field of study and career aspirations. Engineering and science students who aspire to be researchers are more likely to think they will be in such an environment. Although most of the respondents believe that Japan is affected by globalisation, many did not personalise globalisation. There is a tendency to see globalisation as an abstract concept which one does not have to engage with. This is possibly related to what Burgess (2013) describes as something rooted in an insular world view that sees globalisation as an external process, something owned by somebody else.

The data is described in the next section, followed by the presentation of the main findings and discussion, and finally the conclusion.

\section{The study}

The data for this paper was collected over the course of 18 months or three semesters at Nagoya University, a top Japanese national university. Nagoya students are generally thought of as being academically-inclined. The students in the English classes for first and second year undergraduates taught by the author were surveyed near the end of each semester for three semesters. For convenience, I will refer to the surveys as Survey 1, 2 and 3 according to the chronological order of the semesters. The questionnaires were developed by the author and consisted of Likert-type statements on globalisation (e.g. 'I want to be able to function in an international environment.') written in Japanese. There was also space after each statement for comments. The usual ethical guidelines were followed and the students were told that the survey was part of the author's research on globalisation and that participation was voluntary and had nothing to do with the class or their grades.

The statements in the three questionnaires used in Surveys 1, 2 and 3 varied to some degree, but the theme of this paper, whether students think they will be in an international environment (represented by the statement 'I think I will be in an international environment'), was included in all three surveys. This is partly because the responses were intriguing and difficult to make sense of, and partly because of the enormity of its implications on the effectiveness of an internationalised curriculum. The other results of Surveys 1 and 2 are presented in Morita, 2013a and Morita, $2013 b$.

A total of 217 students were surveyed in the three surveys. In Survey 1, $n=54$, consisting of 18 engineering students, 20 literature students and 16 science students. In Survey 2, n=109, made up of 18 agricultural science students, 33 engineering students, 38 health sciences students and 20 law students. In Survey 3, n=54, which consisted of 19 engineering students, 19 literature students and 16 science students. When the numbers for all three surveys are combined, there are 18 agricultural science students, 70 engineering students, 38 health sciences students, 20 law 
students, 39 literature students and 32 science students.

\section{The main findings and discussion}

On the whole, $53.9 \%$ of the 217 students think they will be in an international environment, $45.2 \%$ disagree, $0.5 \%$ is neutral and $0.5 \%$ did not respond. In Survey 3 , the respondents were asked to write about why they think they will or will not be in an international environment. Their responses were analysed and the author found that some responses were on one topic (counted as one comment) but others were on two topics (counted as two comments). Analysed this way, a total of 65 comments were found in the data. The comments were read through again and grouped under different themes. The main themes that emerged are also the factors that influenced the students' answers to whether they think they will be in an international environment. The main themes or factors are: field of study and career aspirations (22 comments or 33.8\%), globalisation (13 comments or $20 \%$ ), desire or requirement to work abroad (8 comments or $12.3 \%$ ) and international aspects of future job (7 comments or 10.8\%).

\subsection{Field of study and career aspirations}

This is the most influential factor (22 comments or 33.8\%) on students' answers as to whether they think they are going to be in an international environment. Many engineering and science students think they will be performing research-related work in universities or outside universities (10 comments or 15.4\%), which they perceive as something taking place in an international environment:

'I am involved in engineering and information science, so I will definitely work overseas. It is necessary to work in an overseas branch and cooperate with foreign companies.'

'I am a physics student and want to work in a job related to the field. One cannot achieve that in Japan: research in a foreign language and interaction with foreign researchers are unavoidable.'

'Since I may work in a university research project team or research institute, I need to interact with researchers of various fields at the forefront of research and read papers in English.'

'I intend to research physics (particle physics) and need to present my papers to an international audience.

Moreover, cooperation with other universities and institutions is not limited to Japan but worldwide.'

The first two respondents perceive their professional fields as borderless and advancing their careers beyond the boundaries of Japan as inevitable. The third and fourth do not mention going abroad directly but write about collaborating with foreign colleagues and institutions as well as reading and presenting papers at international conferences.

It is important to emphasise here that it is the student's perception of whether a certain profession operates in an international setting which influences his/her answer as to whether he/she will be in an international environment. The following example illustrates this clearly. One student aspires to be a teacher and his/her perception of the school environment as international leads him/her to think that he/she will be in an international context:

'I want to be a teacher in Japan in future. Even at the moment, many foreign students are studying in Japanese schools. I am sure more foreign students will come to Japanese schools, and every class may have at least one foreign student in future.'

The above respondent believes that with increasing numbers of foreigners in Japan, more of their children will attend public schools. On the other hand, five other students who also want to be teachers see the school environment as exclusively Japanese and this makes them think they will not be in intercultural contexts:

'I want to be a teacher of Japanese in a Japanese high school in future. If this comes true, I won't be in an international environment.'

The view that Japanese public schools are for the Japanese only is clear above. The present author is inclined to agree with the former view that Japanese public schools are becoming increasingly international with more children from international or non-Japanese-speaking backgrounds. (Castro-Vazquez, 2011)

Other professions which the students associate with an international environment are: working in an airport (1 comment), being a civil servant (1 comment), working in foreign affairs (1 comment) and working in tourism (1 comment). One other occupation which a respondent associates with a Japanese-only context is working in a town or city council.

The preceding discussion makes one suspicious of whether students from engineering and science are more likely to think they will be in an international environment. Starting with the department with the highest proportion of students who think they will be in intercultural contexts, the figures from all three surveys combined are: engineering 
$70 \%$, science $62.5 \%$, agricultural science $55.6 \%$, literature $51.3 \%$, law $45 \%$ and health sciences $23.7 \%$. Apart from health sciences students, there is a pattern of the numbers from engineering and science faculties being higher than literature and law numbers. Students from engineering and science may perceive their future environment as being more international than literature and law students. Based on the responses in this section, engineering and science students see themselves working at the forefront or cutting edge of technology which they perceive as something involving international collaboration but literature and law students do not. It is also interesting why health sciences numbers are closer to literature and law than to engineering and science. This requires further study.

\subsection{Globalisation}

13 comments $(20 \%)$ cite the increasing interconnectedness of the world as the reason their authors think they will be in an international environment:

'Japan is connected to the world in every field, and it needs to continue global activities.'

'Problems which cannot be solved by one country will increase, so globalisation will continue and everybody will be international.'

'Many Japanese corporations have started business abroad, while many foreigners, particularly Asians, have come to Japan for a job. Therefore, once I start working, I will definitely have opportunities to interact with foreigners.'

The first respondent perceives Japan as being connected to the world in every way while the second sees all nations working together on global problems. The third refers to Japanese businesses expanding abroad and foreigners seeking employment in Japan.

\subsection{Desire or requirement to work abroad}

Eight comments (12.3\%) are on the student's desire to work abroad or being sent abroad by one's employers:

'I want to work in a company or a department where dealings with overseas business are required, which is because I want to visit many countries.'

'If my company requires me to go abroad, I will be in such an environment.'

'Japan is small while the market expands worldwide. It is quite possible to be sent abroad once I start working for a company.'

The first comment expresses a desire to be sent abroad to work while the other two show willingness to comply if instructed to do so.

\subsection{International aspects of future job}

Seven comments $(10.8 \%)$ are about the international aspects of one's future job putting one in an international environment:

'Nowadays it is getting rare to find jobs which have no international dealings, and the job which I will get in future is certain to be in an international setting.

The respondent thinks that most jobs in the job market involve international work.

The students may be right about having international aspects to their future jobs according to a recent Japan External Trade Organization (JETRO) survey. (JETRO, 2013) In addition to the current strong presence of Japanese businesses internationally, the study of 1,957 small- and medium-sized enterprises found that about $70 \%$ are very motivated to explore overseas markets by exporting or direct investment, thereby increasing the future foreign-related workload of employees.

\subsection{Sakoku ('closed country') mentality}

In Survey 2, the students were asked if they thought that Japan was affected by globalisation and $89 \%$ answered in the affirmative. Although $81.7 \%$ disagreed with the statement that staying in Japan meant they were not affected by globalisation, responses such as that below hint that there are some, albeit a minority, who seem to be influenced by the sakoku mentality:

'(Globalisation) depends on people. Some may want to continue to live in their country.'

In the comment above, the respondent implies that national boundaries protect one from globalisation and that it is only when one chooses to step outside these boundaries that one is affected by globalisation. In other words, Japan is closed to globalisation and Japanese who stay in Japan are safe from it. This contrasts sharply with discussions in the literature on globalisation about how unstoppable and beyond one's control it is. Stiglitz (2002), for instance, is 
concerned about the direct effects of globalisation on the lives of ordinary people precisely because they are beyond their control. The following responses from Survey 3 also show some sakoku influence:

'Japan is closed to or isolated from other countries, so unless one ventures to work abroad, such as working for a global company, he or she won't have such an opportunity (to be in an international environment).

'I am going to be a teacher of Japanese to Japanese students, so it is very unlikely to work overseas, and interact with people abroad.'

The first comment implies that Japan is a closed country and international contexts exist outside Japan only. The second expresses the view that there are only Japanese people in Japanese public schools and since he/she will probably not be sent abroad, he/she will not interact with foreigners.

\subsection{Not personalising globalisation}

Another finding that emerged from the surveys shows that students are unable to personalise the experience of globalisation. They know about globalisation and understand what it is as an abstract concept but they do not see it as something affecting their lives in reality. This can be seen in a pattern described below which can be seen in both Surveys 1 and 2. When asked whether it was important to be able to live and work in an international environment, $81.5 \%$ of the students in Survey 1 agreed and $18.5 \%$ disagreed. This was a question about an abstract idea, about the ability to function in an international environment theoretically or in principle. Respondents who agreed it was important wrote:

'I think it is important because the world is becoming increasingly globalised.'

'Business overseas is becoming an important source of revenue.'

'Since Japan lacks natural resources, we cannot maintain good living standards like now unless we do business with foreign countries.'

'It is important to interact with the world.'

The respondents feel it is important to be able to function in intercultural contexts because of the world becoming increasingly interconnected, profits from overseas business, Japan's relative lack of natural resources and the importance of interacting with the outside world. In another question, the wording of the statement was changed slightly to ask the students if they wanted to be able to live and work in an international environment. The proportion of those who agreed fell to $53.7 \%$ and those who disagreed rose to $46.3 \%$. Finally, the respondents were asked more directly whether they thought they would be in an international context and $50 \%$ answered in the affirmative and $50 \%$ in the negative. The same pattern can be found in Survey 2, where $93.6 \%$ agreed it was important to be able to function in an international environment, $62.4 \%$ wanted the ability and $47.7 \%$ thought they would find themselves in such an environment. The indifference towards globalisation is clearly expressed in the following response:

'I, who want to be an English teacher, will teach internationalisation to future students, but personally it does not affect me at all."

To the respondent, globalisation is an abstract concept which is taught in school but not put into practice. It is something which he/she as a teacher would teach professionally but not believe in personally.

The author at first suspected that the students' inability to relate personally to globalisation to be due to the lack of foreigners in their daily life, based on comments that there were no foreigners around them. She found that there were 67,322 foreigners in the city of Nagoya, or $3 \%$ of the total population of 2,258,908, which is not a small number for the fourth largest city of Japan. (Office of the Mayor, City of Nagoya, 2010) The numbers of international students in the respondents' immediate environment, the university, were not low either. According to official university statistics, $16.5 \%$ or 1,611 of the undergraduate population of 9,783 are international. At Law, $20.1 \%$ or 138 of the 685 undergraduates are international; at Engineering, $10.5 \%$ or 359 of 3,405; at Agricultural Science, $7.7 \%$ or 57 of 741; and at Medicine and Health Sciences, $6.4 \%$ or 99 of 1,544. (Nagoya University 2013)

A more likely explanation would be the lack of contact or intercultural interaction with international students, based on 10 years' experience and observation at the university. The presence of international students does not necessarily mean that meaningful interaction is taking place between them and Japanese students. International students at Nagoya University gain admission either via the English language or Japanese. Those who come in via English usually take English-taught classes only where there are few or no Japanese students. The numbers of these international students are growing due to the G30 programme, which is a government project launched to increase the number of international students to 300,000 by the year 2020, mainly by opening English-medium courses and 
programmes. This project, in principle, enables Japanese universities to compete with universities in English-speaking countries for top international students, but in reality, segregates international students from domestic students and deprives both of invaluable opportunities for intercultural interaction. This explains why $76 \%$ of Japanese students at Nagoya University said there are few or no international students in their classes. (Morita, 2012) Opportunities for intercultural interaction outside the classroom are also few and far between. International students in English-taught programmes are very limited in their Japanese social circles. The only Japanese they interact with are those who man the helpdesk and students from a student organisation which provides support for international students.

\section{Conclusion}

There may be difficult times ahead for Japan. The G30 project is bringing unprecedented numbers of international students to the country but intercultural aspects of internationalisation such as reciprocal intercultural understanding and inclusive social practices have been neglected. With intensified globalisation and multinational work environments, there will be a lot of contact between Japanese and people from other cultural backgrounds. This challenge is compounded by the aging Japanese population and the demographic changes that will result from immigration of foreign workers to supplement the Japanese workforce. Cultural norms in Japanese schools will also change as a result of rising numbers of non-Japanese students becoming part of the school population.

It is encouraging to have found in this study that although a minority of young Japanese are influenced by sakoku thinking, many are outward-looking, and they look forward to collaborating with foreigners, working within Japan in an international environment, working abroad or making business trips to other countries.

The finding that students do not personalise the experience of globalisation requires further study to find out why they do not think they will be in intercultural contexts. Whether this is related to the neglect of the intercultural aspects of internationalisation also needs further research.

We have seen that literature and law students are less likely to perceive themselves working in an international environment. If this is true of most of the literature and law students, the university needs to help them change this perception and there is some urgency in the matter. As the university is internationalising its curriculum and trying to prepare students to function in intercultural contexts, the effectiveness of the curriculum would be compromised if students do not think they will be in an international environment. Among other measures, lecturers in literature and law should be encouraged to introduce to students the international aspects of their prospective careers. Incentive structures such as extra credits should also be developed to encourage students to play an active role in globalisation.

Intercultural interaction should be as widely encouraged as possible. Its benefits will soon be recognised:

'I myself joined AIESEC (a global youth network) and interacted with foreign people. I find it very rewarding, so I want to work in an international environment in future.'

Having positive experiences such as those described by the respondent will encourage young people to seek out intercultural contexts. In addition, intercultural interaction will also help students personalise globalisation. It is a privilege that the university has such a large international student community and it is the university's responsibility to help both Japanese and international students engage each other.

\section{References}

Burgess, C. (2013, May 21). Ambivalent Japan turns on its 'insular' youth: system discourages overseas study but students get blame. The Japan Times. [Online] Available: http://www.japantimes.co.jp/community/2013/05/21/issues/ambivalent-japan-turns-on-its-insular-youth/

Burgess, C., Gibson, I, Klaphake, J. \& Selzer, M. (2010). The 'Global 30' Project and Japanese higher education reform: an example of a 'closing in' or an 'opening up'? Globalisation, Societies and Education 8(4), 461-475. http://dx.doi.org/10.1080/14767724.2010.537931

Castro-Vazquez, G. (2011). The educated citizen: cultural and gender capital in the schooling of Latin American children in Japan. Journal of Research in International Education 10(3), 244-260. http://dx.doi.org/10.1177/1475240911420525

Clammer, J. (2001). In but not of the world? Japan, globalization and the 'end of history'. In C. Hay \& D. Marsh (Eds.), Demystifying globalization (pp. 147-167). Basingstoke: Palgrave.

Dougill, J. (1995). Internationalization - as if it mattered. In K. Kitao (Ed.), Culture and communication (pp. 61-73). Kyoto: Yamaguchi Shoten. 
Goodman, R. (2007). The concept of Kokusaika and Japanese educational reform. Globalisation, Societies and Education 5(1), 71-87. http://dx.doi.org/10.1080/14767720601133413

Hamza, A. (2010). International experience: an opportunity for professional development in higher education. Journal of Studies in International Education 14(1), 50-69. http://dx.doi.org/10.1177/1028315308329793

Itoh, M. (2000). Globalization of Japan: Japanese sakoku mentality and U.S. efforts to open Japan. Basingstoke: Macmillan.

Japan External Trade Organization (JETRO). (2013). Results of JETRO's FY2012 survey on the international operations of Japanese firms. Retrieved August 24, 2013, from http://www.jetro.go.jp/en/news/releases/20130328200-news?print=1

Knight, J. \& de Wit, H. (1995). Strategies for the internationalisation of higher education: historical and conceptual perspectives. In H. de Wit (Ed.), Strategies for the internationalisation of higher education (pp. 5-32). Amsterdam: EAIE.

Montgomery, C. (2009). A decade of internationalisation: has it influences students' views of cross-cultural group work at university? Journal of Studies in International Education 13(2): 256-270. http://dx.doi.org/10.1177/1028315308329790

Morita, L. (2012). English and intercultural interaction in the internationalisation of a Japanese university. Journal of Intercultural Communication 30. [Online] Available: http://www.immi.se/intercultural

Morita, L. (2013a). Globalisation, intercultural contexts and the sociocultural component of an English course. Journal of English as an International Language 8(1), 55-68.

Morita, L. (2013b). Japanese university students' attitudes towards globalisation, intercultural contexts and English. World Journal of English Language 3(4).

Nagoya University. Retrieved February 22, 2013, from http://www.nagoya-u.ac.jp/about-nu/history-data/figure/

Office of the Mayor, City of Nagoya. (2010). Nagoya foreign residents survey results announcement. Retrieved 22 February, 2013, from http://www.city.nagoya.jp/en/cmsfiles/contents/0000023/23403/english.pdf

Stiglitz, J. (2002). Globalization and its discontents. New York: W.W. Norton.

The Council on Promotion of Human Resource for Globalization Development. (2011). An interim report of the Council on Promotion of Human Resource for Globalization Development. Retrieved August 24, 2013, from http://www.kantei.go.jp/jp/singi/global/1206011interim_report.pdf

Whitsed, C. \& Volet, S. (2011). Fostering the intercultural dimensions of internationalisation in higher education: metaphors and challenges in the Japanese context. Journal of Studies in International Education 15(2), 146-170. http://dx.doi.org/10.1177/1028315309357941

Whitsed, C. \& Wright, P. (2011). Perspectives from within: adjunct, foreign, English-language teachers in the internationalization of Japanese universities. Journal of Research in International Education 10(1), 28-45. http://dx.doi.org/10.1177/1475240910396332

Yamagami, M \& Tollefson, J. W. (2011). Elite discourses of globalization in Japan: the role of English. In P. Seargeant (Ed.), English in Japan in the era of globalization (pp. 15-37). Basingstoke: Palgrave Macmillan. 